\title{
Measuring School Capacity, Maximizing School Improvement
}

Jessica K. Beaver

University of Pennsylvania, jessica.k.beaver@gmail.com

Elliot H. Weinbaum

University of Pennsylvania

Follow this and additional works at: https://repository.upenn.edu/cpre_policybriefs

Part of the Educational Assessment, Evaluation, and Research Commons, and the Education Policy Commons

\section{Recommended Citation}

Beaver, Jessica K. and Weinbaum, Elliot H.. (2012). Measuring School Capacity, Maximizing School Improvement. CPRE Policy Briefs.

Retrieved from https://repository.upenn.edu/cpre_policybriefs/41

View on the CPRE website.

This paper is posted at ScholarlyCommons. https://repository.upenn.edu/cpre_policybriefs/41

For more information, please contact repository@pobox.upenn.edu. 


\title{
Measuring School Capacity, Maximizing School Improvement
}

\author{
Abstract \\ Given the nearly ubiquitous use of the term "capacity" in education policy discourse, this policy brief \\ offers a common framework for analyzing capacity that educators, policymakers, and researchers alike \\ can apply and understand with consistency. Drawing data from a larger three-year CPRE study of school \\ responses to accountability in Pennsylvania, the authors' goal is not to provide an easy, new, one- \\ sentence definition, but rather to create a shared language that can be applied to research and \\ improvement efforts in schools. To accomplish this, the authors break capacity down into component \\ parts, explaining how each one builds off the next and contributes to theoverall concept.

\section{Disciplines} \\ Educational Assessment, Evaluation, and Research | Education Policy

\section{Comments} \\ View on the CPRE website.
}




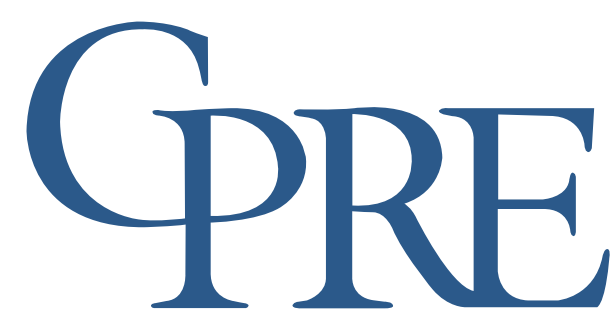

CONSORTIUM FOR POLICY RESEARCH IN EDUCATION

\section{Measuring School Capacity, Maximizing School Improvement}

Jessica K. Beaver and Elliot H. Weinbaum

\author{
Graduate School of Education \\ University of Pennsylvania
}

It is an oft-heard refrain in schools: "These schools lack the capacity they need." Or, "We need to build capacity in schools so that students can achieve." In district offices, statehouses, and elsewhere, the sentiment is repeated in various forms, but the term "capacity" is almost always used. But what do education leaders mean when they use the word capacity? Some people use the word to mean the intangible behaviors or characteristics that are needed for a school to improve, while others use capacity as a synonym for ability or knowledge. Meanwhile, economists often talk about capacity in terms of quantities or outcomes that an organization is able to produce.

Given the nearly ubiquitous use of the term in education policy discourse, we offer a common framework for analyzing capacity that educators, policymakers, and researchers alike can apply and understand with consistency. Our goal is not to provide an easy, new, one-sentence definition, but rather to create a shared language that can be applied to research and improvement efforts in schools. In this Policy Brief, we break capacity down into component parts, explaining how each one builds off the next and contributes to the overall concept. Our hope is that the four research-based components we suggest human capital, social capital, program coherence, and resources (building on Hatch, 2009; Elmore, 2000; Fullan, 2000; Spillane \& Thompson, 1997; Corcoran \& Goertz, 1995) - will stimulate discussion of a widely accepted meaning of capacity in both research and practice.

Our secondary goal is to demonstrate what it means to be a high-, medium-, or lowcapacity school. Accordingly, we apply our components-based definition to data collected from 11 schools in Pennsylvania. After using the approach designed to assess school capacity, we classify each school as high, medium, or low and identify themes from the three resulting groups. This applied analysis allows us to provide a descriptive illustration of the strengths, weaknesses, opportunities, and challenges of each classification.

Our data are drawn from a larger three-year CPRE study of school responses to accountability in Pennsylvania. In that study, schools were randomly selected for in-depth case studies based on their performance on the state standardized test and whether they were elementary or high schools. The resulting sample contains a wide breadth of schools. The common thread, however, is that nine of the schools were identified by the state, under guidelines required by No Child Left Behind (NCLB), as needing to improve their scores on the state test following the 2007-2008 school year. In other words, these are precisely the schools for which capacity levels matter greatly.

To summarize our findings; we found that our components-based definition of capacity could be easily and clearly applied to our sample of schools. When looking in depth at the themes that emerged from these groups, we found that performance on the state test did not necessarily 


\section{GRE}

correlate well with capacity levels - our sample contained high-performing schools with relatively low levels of capacity, as well as low-performing schools with high levels of capacity. (Though it would be useful to know whether capacity was related to the value added by schools; that question remains to be answered by future research.) Finally, we were able to identify the unique challenges and opportunities of the mid-capacity schools, which is a set of schools that is often overlooked as policymakers focus on the most struggling schools.

The implications for these findings are important for practitioners and policymakers alike. For the practitioner, a common framework for analyzing capacity allows for improved pinpointing of school weaknesses and better targeting of improvement strategies. By breaking capacity into its component parts, practitioners may also realize that pursuing efforts in one area of weakness may not be enough in some schools, efforts may need to take place in several of the four capacity components in order to produce meaningful changes. Policymakers and other education stakeholders also benefit, as a common definition will allow them to consider new ways of improving schools with greater understanding and specificity. If policymakers were to consider school capacity levels prior to the selection or implementation of an improvement program, it may help to improve the appropriateness of the program selected, as well as the implementation of the program.

The research reported here was supported by the Institute of Education Sciences, U.S. Department of Education, through Grant R305A080280 to the University of Pennsylvania. The opinions expressed are those of the authors and do not represent views of the Institute or the U.S. Department of Education.

This brief has been internally and externally reviewed to meet CPRE's quality assurance standards. All data presented, statements made, and views expressed are the responsibility of the authors and do not necessarily reflect the position of the Consortium for Policy Research in Education, or its institutional partners.

\section{School Capacity for Improvement}

Education experts have long been grappling with the concept of capacity in schools. Their definitions vary in terms of the outcome variable of interest (i.e. capacity for what?) and the unit of analysis (i.e. capacity for whom?). In terms of the outcome variable, some authors (Spillane \& Thompson, 1997; Corcoran \& Goertz, 1995) describe capacity as the discrete characteristics that enable a school to bring about effective change, while others (Hatch, 2009;

Newmann, King, \& Youngs, 2000) define capacity more specifically as the "collective competency" or "investment" necessary for a school to improve in a meaningful way. In their work on instructional capacity, Corcoran and Goertz (1995) define capacity in terms of economics, describing it as "the optimal amount of production that can be obtained from a given set of resources and organizational arrangements." Authors also differ slightly in their unit of analysis. While Hatch, as well Corcoran and Goertz, examine instructional capacity at the school level, Spillane and Thompson examine capacity at the level of the school district. Taking a slightly different approach, O’Day, Goertz, and Floden (1995) frame their definition in the context of standards-based reform, defining capacity as the ability of the system of the state-district-school as a whole to enable students to meet academic standards.

As we work to develop a comprehensive definition of capacity, we set forth our own guidelines about our frame and unit of analysis. Since we examine capacity in the context of the performance-based accountability system set forth in NCLB, we are interested in capacity in the service of improving student performance. And, while we recognize the potential importance of district offices, state education agencies, and support organizations in improving student performance, our unit of analysis is the school as the organizational unit of most direct importance.

Using a literature-based definition of school capacity, we identify four main components of capacity: human capital, social capital, program coherence, and resources (Hatch, 2009; Elmore, 2000; Fullan, 2000; Spillane \& Thompson, 1997; Corcoran \& Goertz, 1995). Each of these components is defined and discussed below. 


\section{The Four Components of Capacity}

- HUMAN CAPITAL: The knowledge, skills, commitment, disposition, and intellectual ability of the members of a school's staff;

- SOCIAL CAPITAL: The intangible network of relationships that fosters unity and trust within a school's staff;

- PROGRAM COHERENCE: The degree to which instruction, resources, and staff in the school are coordinated and integrated into a common framework; and,

- RESOURCES: The physical or organizational tools that a school has at its disposal to make its improvement goals a reality.

Human Capital. Human capital can be roughly defined as the knowledge, skills, commitment, disposition, and intellectual ability of the members of a school's staff (Newmann, King, \& Youngs, 2000; Spillane \& Thompson, 1997; Corcoran \& Goertz, 1995). Put in very simple terms, human capital is the amount that a school benefits from having each individual working there, each person with his or her own strengths, weaknesses, and preferences. Although research is inconclusive on the degree to which teacher inputs - such as salaries, experience, or credentials - matter in terms of student achievement, there is some evidence to suggest that teachers' basic skills and subject-matter content knowledge are predictors of student performance (Rockoff, Jacob, Kane, \& Staiger, 2008; Hill, 2007). As such, augmenting human capital would necessitate an investment in the individual staff members. All else being equal, a school in which teachers have high levels of content knowledge, are committed to the school goals, and are deployed effectively will have higher capacity than a school without these features. However, human capital alone does not create school capacity - human capital must be encouraged and developed in concert with other critical components, particularly that of social capital.

Social Capital. Social capital - which has a huge literature base all its own - is the component of capacity that is inherent in the relationships between and among individuals in the school (Hatch, 2009; Spillane \& Thompson, 1997). In their work on relational trust in schools, Bryk and Schneider (2002) list four elements that make up social capital: the fostering of mutual understanding, the development of collective competence, the fostering of care and concern among staff, and support for integrity and the alignment to mutual goals. Similarly, Gamoran, Gunter, and Williams (2005) cite the hallmarks of social capital as trust, reciprocity, the flow of information, and support for emerging norms. As mentioned above, social capital is closely linked to human capital - without social capital, the skills and expertise of staff are not shared and therefore remain trapped at the individual level and cannot be leveraged for ongoing organizational improvement. In their recently published book, Hargreaves and Fullan (2012) combine the two concepts of human and social capital into one concept that they call "professional capital," which they believe can have a transformative effect on school and system-wide improvement. There is some evidence to suggest that they are correct, as Bryk and Schneider (2002) have found that schools in which staff is well trained and trust levels were high were more likely to experience student performance gains.

Program Coherence. Program coherence is explicitly mentioned in some discussions of school capacity and left out of the equation by others. Among the four components discussed here, its meaning has been the least explicated in previous literature. The clearest definition is provided by Newmann et al. (2001), who describe program coherence as being present when three conditions are met within a school. First, the school must possess common instructional frameworks that guide teaching, learning, curriculum and assessment. Second, working conditions for staff in the school must support the incorporation of the instructional frameworks into practice. Third, the school must devote the necessary time and resources to fully implement the common instructional frameworks. 
Newmann et al. (2000) sum up program coherence as "the extent to which the schools' programs for student and staff learning are coordinated, focused on clear learning goals, and sustained over a period of time" (p. 5). What these descriptions highlight is that simply having the highly skilled and knowledgeable staff who related well to each other is not enough - instructional programs must be carefully woven into the existing instructional fabric in order to become effective learning tools. Similar to the findings for social capital, Newmann et al. (2001) report that higher levels of program coherence are also associated with student performance gains.

Resources. The resource component of capacity is a bit unlike the others. Whereas the defining characteristics of human capital, social capital, and program coherence are clearly identified in the literature, there are no agreed upon characteristics of capacity-building resources. Newmann et al. (2001) list the resources that schools with high capacity usually possess, including high-quality curriculum, instructional material, assessment instruments, classroom technology, and workspace. Others, such as Corcoran and Goertz (1995), expand the scope of resources to include organizational factors such as adequate staffing levels, instructional support, professional development, and class size. The reason for these discrepancies is that resources only build school capacity if they are used properly and in a way that supports the other three components. In other words, physical resources alone are inanimate objects; it is when they are deployed in support of the other forms of capacity that they allow the school to improve.

\section{Data}

Our study sample consists of 11 elementary and secondary schools throughout Pennsylvania that were selected for in-depth site visits to better understand school improvement efforts and the context in which they occur. From an accountability standpoint, most schools in the sample ( 9 out of 11) were identified by the state as in need of improvement due to performance of at least one subgroup following the 2007-2008 school year. Schools were selected using a stratified random sample, but also took into account student demographics and geographic location to ensure statewide representation. The interviews for this study took place during the spring of 2009.

Qualitative case study data were gathered from these 11 schools through in-person interviews with school principals, administrative staff, teachers, and other support personnel. The number of interviewees in each school ranged from five to ten people. All interviewees were asked basic background questions about their school's context, including explanations for student performance, the nature of the surrounding community and internal school culture. Interviewees were then asked in-depth questions about the various activities and strategies underway in the school in response to the performance-based accountability pressures set forth in NCLB.

\section{Applying the Literature-Based Definitions}

The four components of capacity outlined above create a blueprint for a framework that can be applied in school-level analyses. The capacity components contain many overlapping features and are, in some cases, mutually reinforcing. For example, program coherence requires the integration of various services within the school and is greatly improved if the school possesses a well-prepared staff (human capital), as well as shared norms and goals (social capital). Similarly, resources should be viewed as important tools in bolstering the other three components of capacity. Therefore, resource deployment must be analyzed by the extent to which the resources in question were used to reinforce a comprehensive notion of school capacity.

Using these four components as an analysis frame, we looked at each of our 11 schools to determine whether they were high-, medium-, or low-capacity schools. To do this, we applied a formal rubric that aggregated school ratings for each of the capacity components described above to create an overall capacity rating. To our knowledge, this is the first attempt to formally categorize schools as high-,medium-, or low-capacity based on a formal framework and rubric. The process contained three steps. 
First, responses from the individual interviews were aggregated to the school level, with each school rated as to the presence or absence of the identified subcomponents of capacity (taken from the literaturebased definitions above). Within the human capital component, we looked at the individual staff members' explicit strategies for student learning, as well as their familiarity with (and adherence to) the school goals and mission. For the social capital component, we looked at staff members' collective understanding of the school goals and mission, as well as the degree of communication within the school and between the school and the community. For the program coherence component, we looked at the degree of alignment of supplemental services, the degree of integration of instructional frameworks, and the quality of the curriculum. Finally, for the resources component, we looked at the quality of the curriculum, the adequacy of school facilities, the student-to-teacher ratios and staffing levels within the school, and the quality of professional development.

In the second step, we linked the ratings of each sub-component to the four key components of capacity - human capital, social capital, resources, and program coherence - and assigned a rating of high, medium, or low in each component area. Finally, we aggregated school ratings in each of the four components once more to obtain an overall school capacity rating. High ratings were reserved for those schools that exhibited high levels in at least two of the capacity components and no low ratings in the other two categories. Low-capacity schools were those with low ratings in at least two of the categories. The remaining schools fall in the medium range.

Using this method, the 11 schools in our sample were categorized as follows: four schools rated as "high," four schools as "medium," and three schools as "low." Once schools had been categorized on the basis of their overall capacity levels, the next step was to look at themes within capacity categories to develop a comprehensive understanding of what it means to be a high-, medium-, or low-capacity school.

Interestingly, we found no relationship between school performance, or Adequate Yearly Progress (AYP) status under NCLB, and school capacity as measured with this framework. For example, there was one school in our sample that has made AYP for many years and was found to be a medium-capacity school, while another school that failed to make AYP in multiple subgroups was found to be a highcapacity school. The absence of a relationship between capacity and performance status will be discussed further in the summary section of this brief.

High Capacity. Beginning with the high-capacity schools, we found that these schools were well positioned with regard to all of the capacity components. In terms of human capital, they all had highly dedicated staff that had a clear vision of the schools' goals for their students. Teachers were highly committed to their students' success in school and they reported receiving support in various forms - through formal and informal mentoring, inservices, the assistance of support staff, and supplemental learning material. Teachers felt that they would be supported in the future should they need additional help.

"They are friendly people, caring people and the kind of school I envisioned when I thought about being a principal. That it would be a school where folks cared about one another and cared about the kids that were in the building and did their best to make it a family environment."

- Principal of a high-capacity elementary school.

In terms of social capital, these schools all nurtured a strong team environment. As the principal of one high-capacity school put it: "I look forward every morning; I wake up and can't wait to come here. There are quite a large amount of us who come in at 7:00 in the morning. We don't have to be here until 8:20 and a lot of us stay after. We just do what we need to do but we like being around each other; we like to socialize together; we are really close." Staff in all four schools reported that they met regularly to discuss instructional strategies, program implementation, student data, and other issues. For elementary schools, these meetings were conducted through grade-level team meetings, and for high schools they were usually done by subject area. Three of the four high-capacity schools had formal structures in place to facilitate collaboration, such as 
Professional Learning Communities (PLCs) or common preparation periods for teachers. The feeling among staff in all four schools was that they were working together toward common goals, and were ready to step in and support any member of the staff who was struggling.

In terms of program coherence, teachers in the high-capacity schools reported that they made efforts to align their instruction with that of their colleagues. The high-capacity schools also worked to identify struggling students and provide remediation and support services that were appropriate for their needs and aligned to the instructional and curricular programs already in place in the schools. Although all four schools had active remediation programs, two excelled in this area by instituting Response-to-Intervention ( $\mathrm{RtI}$ ) systems for identifying and targeting struggling students. These RtI programs used benchmark testing data to identify struggling students in a particular area, which the school would then use to target remediation on a one-to-one basis.

In terms of resources, three of the four schools were from high-wealth districts and reported that they had ample materials to support their educational goals. One high-capacity school did not have access to expensive materials and had low-achieving students. While students in other high-capacity schools were using technology resources almost at a one-to-one level, teachers in this school had to sign up for a laptop cart, which was wheeled from classroom to classroom and in very high demand. In the other schools, class sizes were generally small and support staff was robust, while the chief complaint of teachers in this school was that class sizes were far too big and that the school lacked language support for incoming immigrant refugee students. Despite its relative lack of resources, this school with lowachieving students was still able to draw upon the high levels of social capital in the school to leverage the scant resources at its disposal and use them to support its mission and goals. This accomplishment was especially noteworthy because this school had failed to meet its accountability goals in several areas. While the relatively low academic performance of its students on the state tests might in other schools become a source of overwhelming anxiety or stress, the staff in this school chose to view their accountability status as a rallying point for collective action for improvement.

Medium Capacity. The medium-capacity schools are perhaps the most difficult group of schools to characterize, which may also explain why they are seldom discussed in other research. These schools are often overlooked in discussions of schoolwide capacity, perhaps because some of the schools in the set can appear to be like low-capacity schools, whereas others can appear to be like high-capacity schools. Given the diversity of capacity characteristics, it is more difficult to find commonalities among the medium-capacity schools. In our sample of four medium-capacity schools, however, we did find some commonalities worthy of discussion.

In terms of human and social capital, the theme that emerged from the data was that all four schools had at least one staff member who emerged as a champion of student learning and played a critical role in defining the culture of the school. This is different from both the high-capacity schools and the low-capacity schools. Champions may have existed in high-capacity schools, but their efforts did not stand out dramatically from the staff's collective pursuit of shared goals. Low-capacity schools, on the other hand, lacked vocal champions of organizational improvement; people may have had lofty individual goals, but they did not translate to the goals of the school as a whole. The mediumcapacity schools in our sample were distinguished from the rest because these champions manifested a potential for collective commitment to shared goals that had not yet been fully realized.

Low levels of social capital within the mediumcapacity schools made it difficult for these champions to successfully meet their goals, however. In one medium-capacity high school, teachers were highly skeptical of the motives of the administrative team, and administrators felt that they were missing out on opportunities to engage the staff in collaborative efforts. One administrator at this school noted the following: 
"People look at the building and go,

'it must be the best place around.' I

think there is a lot of room for growth among all staff members, including administrators, all of us across the board. There are phenomenal people here but I don't think their potential has been tapped fully....At the staff level, I think it is a matter of learning the expertise of other staff members; to actually get a chance to share what is going on; get rid of the isolation that is typically in the classroom."

- Administrator at a medium-capacity high school.

In another school, the champion for student achievement was the coordinator for a curriculum program, which was disliked by most of the teaching and administrative staff. Champions of change in medium-capacity schools tried to improve the quality of teaching and learning (and some did get some traction in establishing shared norms and values), but their efforts were ultimately stymied by a general lack of faith in the programs for improvement and in other leadership or colleagues in the schools. While it is possible that these champions of change might one day reach the "tipping point" and make their individual goals into schoolwide goals, they had not been able to reach this point yet, which stymied their school's overall capacity for change.

In terms of program coherence, the mediumcapacity schools exemplified a culture focused on integrating skills and instructional frameworks, but only across a narrow set of parameters. These schools seemed keen on making test preparation strategies uniform across the curriculum, for example using "problems of the day" or "adopting an assessment anchor." Rarely, however did these efforts touch the instructional core of learning. The same could be said for supplemental services. Afterschool programs and in-school tutoring were both highly focused on improving student achievement on the state standardized test. Cohesion existed mostly around tested subjects, tested grades, and the set of "bubble students" who might be able to improve their scores with minimal input.
Finally, in terms of resources, all four schools seemed to have generally high-capacity facilities, adequate staffing levels, and readily available professional development opportunities. Most of the schools had a high-quality, research-based curriculum in place as well, although in two of these schools the curriculum was severely undermined by the staff's disdain for its instructional approach. Regardless, it appeared that medium-capacity schools all had a reasonable level of resources. That said, the potential for resources to be used in a way that improved human capital, social capital, or program coherence was usually left untapped.

Low Capacity. Finally, we turn our attention to the low-capacity schools. If the high-capacity schools were those in which teamwork and shared goals prevailed, the low-capacity schools could be described as possessing the opposite outlook efforts were disjointed, staff was isolated from one another, morale was low, and non-instructional issues such as student discipline and facility maintenance seemed to trump concerns about the quality of instruction.

In terms of human capital, a recurring theme in our three low-capacity schools was that teachers and staff felt that their efforts to improve the quality of instruction would be useless no matter how hard they tried. Staff frequently attributed poor student performance to factors outside of their control, such as changing community dynamics or demographics, the faltering economy, and low levels of parental involvement. They had trouble articulating school goals aside from the immediate goal of making AYP on the state standardized test. Despite the generally low levels of commitment to school goals or strategies for improving student learning [elements of human capital], a small subset of teachers existed in two low-capacity elementary schools who articulated strategies to help their own students. These teachers felt personally accountable to their students, and were much less likely than their colleagues to blame outside community factors for their students' lackluster achievement levels. These teachers are evidence of the fact that low-capacity schools may still possess motivated and goal-oriented teachers, but that their efforts are highly isolated.

Social capital was predictably low in our three lowcapacity schools. Teachers worked independently from one another, reporting that there was simply 
no time in the school schedule to align instruction, share and discuss student progress, or address instructional challenges or concerns with their colleagues. This low level of social capital meant that the skills and abilities of teachers could not be harnessed in a way that could improve instructional quality across grade levels or subjects. As a result, some staff members with the potential to contribute to the school were left as untapped resources.

Program coherence was also predictably low in these schools, given the disconnected nature of nearly all other activities and programs. When teachers do not communicate and animosity exists between factions of the staff, it becomes extremely difficult to coordinate common instructional frameworks or align supplemental services. None of the three lowcapacity schools had any sort of integrated, sustained instructional frameworks in place, nor did they have coordinated remediation or afterschool programs for struggling students. A teacher at one school explained that the school's strategy was simply to pair up struggling students with teachers on their free periods, working on either remediation or basic test taking strategies. There were no materials or guidelines for these remediation periods.

Meanwhile, the principal would sit down with struggling students every once in a while and give them a pep talk so that they would feel more confident on test day. Although teachers appreciated these pep talks, they did not include explicit strategies to improve learning. As this school's strategy shows, low-capacity schools in our sample instituted short-term and ad hoc programs, hoping that they would meet the diverse needs of their students without necessitating a formal approach to reforming instruction.

In terms of resources, low-capacity schools frequently pointed out the poor quality of the school facilities, large class sizes, and lack of curriculum and professional development support. Staff in one school, which had a high-quality standardized curriculum and ample access to professional development resources, blamed low morale and achievement on the fact that the school was "filthy." The janitor had left the previous year and the school district had yet to replace him. Meanwhile, staff in another school complained accurately - that their curriculum was woefully out of date. They needed new textbooks that were aligned to the state standards if they were to be expected to improve the quality of their instruction, yet the district appeared unsympathetic to their concerns. Finally, our third low-capacity school blamed low student achievement on an exodus of veteran teachers the year before and administrative inconsistencies - there had been three principals in as many years.

\section{Summary}

The descriptions above of high-, low-, and mediumcapacity schools show that the framework composed of the four components described at the start of this policy brief captures quite well the commonalities that exist among schools within one capacity rating. High-capacity schools usually possessed highly committed staff, shared school norms, highly integrated and aligned instructional frameworks, and ample resources. Low-capacity schools were on the other end of the spectrum, with fewer teachers exhibiting a strategy to improve student learning, low levels of cohesion among staff, poorly articulated school norms, poorly integrated instructional frameworks, and a general dearth of resources. Medium-capacity schools, on the other hand, exhibited a mix of capacity characteristics that belied the schools' potential for improvement if critical investments were to be made to support instructional and organizational efforts within the schools and help to create a shared mission and goals. Furthermore, findings from the mediumcapacity schools show that they are distinct from either the high or the low capacity schools, suggesting that future discussions of capacity would benefit from the inclusion of, and perhaps even a focus on, the medium-capacity group.

Additionally, we found that capacity levels do not always accord with identified school performance levels, as indicated by students' scores on the state standardized tests. As mentioned earlier, one of schools labeled as "high capacity" was also a school that was failing to make AYP in multiple subgroup areas on the state test. This discrepancy suggests that school capacity may be a precursor to student performance gains or losses, rather than simply being a correlated measure. Although one might expect a high-capacity school to also be a high-performing school (and, in most cases, we found this to be true), the exceptions to the rule demonstrate that capacity 
is just that - it is the potential that a school has to improve over time. Additionally, the most commonly used school performance measures (including those used in this analysis) do not convey the improvement that schools may show over time or the value they are adding to student learning. These "growth" measures are more likely to correlate with capacity than the "status" measures that are used currently.

Any findings about the capacity levels of schools are, of course, only as good as the measurement and rating tools used to assess capacity in the first place. While we believe our rating tools to be robust, there are a couple of caveats that are worthy of mention. First, in the human capital component of capacity, our study contained no measure of teacher competence. This omission was not accidental; rather, it is a reflection of the fact that there currently exists no universally agreed-upon definition or measurement of teacher competence in the education literature. Since we did not feel that we had a way to accurately measure competence, we omitted it from our data collection and subsequent analysis. Future research, however, might lead to the development of more widely supported measures of individual competency, which in turn would strengthen future capacity ratings of schools.

Another limitation of the study is that the four components of capacity are, as explained before, overlapping and mutually reinforcing concepts. It is also difficult to imagine a school that completely lacks capacity in only a single component area. One might argue, for example, that without physical resources it is impossible to create capacity in any of the other three component areas. Similarly, one could argue that without a modicum of human capital, none of the other areas matters for schools most school leaders would agree that all the trust, coherence, and resources in the world cannot make up for a truly mediocre staff. The same arguments could be made for the other two component areas as well. While parsing out the four areas as separate components of capacity facilitates accurate analysis and the development of improvement strategies, we recognize that the interconnected nature of these elements means that they should not be considered in isolation.

\section{Policy Implications}

These limitations notwithstanding, there are important benefits that can be reaped from the adoption of a common working framework for capacity, both for school-level personnel and for policymakers alike. At the school level, establishing a common framework allows education stakeholders to use the term with greater specificity and increased understanding. Using the framework described here, if an administrator were to say, "We want to get better and improve our scores, but we just don't have the capacity," a suitable response might be, "How so? In what area do you feel that capacity is lacking?" Better targeting of the problem can lead to better solutions for schools and other education entities that are looking to improve their performance.

Another benefit of the components-based definition and framework for school-level personnel is that it demonstrates the interconnected nature of capacity and capacity building. Without the framework, a school that is looking to improve might concentrate its efforts in just one area and ignore the importance of the other three areas. For example, it is a frequent effort in schools to hire the best teachers and staff possible so that students can have access to highly qualified personnel. As the capacity framework suggests, however, hiring the right people without also making sure they are collaborating effectively and trust one another (social capital), are teaching with tools that are integrated into the school's overall improvement mission (program coherence), and are provided with high-quality professional development tools (resources) can mean that overall capacity will suffer.

Benefits of a Common Definition of

"Capacity" in Schools

- Pinpointing of areas of weakness leads to better targeting of solutions

- Demonstrating the interconnected nature of capacity-building efforts

- Reorienting policymaking to focus on specific school needs 
On the other hand, when a school makes a key investment in one component of capacity, that investment can have a spillover effect in other areas of capacity. For example, consider the low-capacity school described above in which the curriculum was outdated and district leadership resisted change. Had that school received new materials (resources), it is probable that teachers would be more likely to stay in the school (human capital), teachers would be more prone to collaborate around material in which they had more confidence (social capital), and the curriculum itself would be aligned to school goals and state standards (program coherence).

Policymakers also benefit from this more specific definition and working framework for capacity. Instead of focusing solely on the distinct programs and strategies that are intended to bring about school improvement, the capacity framework encourages policymakers to think first about the components of capacity in schools. When capacity levels are considered prior to the selection of an improvement program, it may help to improve the quality of the program selected, as well as the implementation of the program later on. For example, if policymakers are looking to incentivize the adoption of a new strategy - we can use small learning communities as an example - it would be helpful to first understand how this new learning arrangement fits into the capacity framework. Will small learning communities encourage collaboration (social capital) or cause more isolation? What types of staff skills are required to make it run effectively (human capital)? How easily can it be integrated into existing school frameworks (program coherence)? What kinds of supports are necessary to make it run effectively (resources)? These questions can help to ensure that new programs and strategies are the right ones given specific school contexts.

On a larger scale, a more specific and applicable definition of capacity can actually change the way that policymakers view school improvement. Currently, the performance-based accountability system in NCLB is designed to focus on the outputs of performance, here measured by state standardized tests. A renewed focus on capacity could help to enhance the way we view improvement in schools, looking at how schools are being run rather than solely looking at their outcomes. Instead of viewing schools in terms of subgroups and numbers, a framework for capacity allows policymakers to home in on the specific areas of strength and deficiency within a school. This approach would allow a much more nuanced approach to school improvement; investing in the types of capacity that are most needed in each school. In conjunction with a performance system that measures the value being added by each school, a system that examines school capacity as defined here would help us to understand that each school faces its own challenges that need to be addressed in different ways.

Creating a school improvement tool that focuses on the capacity components is not an easy task, especially since the capacity components are not always easy to measure. For example, the political controversy surrounding efforts to measure teacher effectiveness (including value-added measures of teacher performance) have highlighted the difficulty in measuring human capital within the school context. Additionally, there already exist several selfassessment tools that are available to schools, which may make it difficult for schools to understand the value of a separate capacity measuring tool. For example, the Indicators for Effective Principal Leadership in Improving Student Achievement in Maryland focuses on the key leadership qualities that principals should possess (MD Dept. of Education, 2010) and the RISC Organizational Self-Assessment Tool allows schools to assess their decision-making process as they attempt to undertake standards-based reform (RISC, 2012). Furthermore, Harvard's Public Education Leadership Project (PELP) has developed a "coherence framework" that districts can use to analyze the degree to which programs and strategies are coherent and aligned to the instructional core (Childress et al., 2007). These types of tools, while helpful for schools, do not serve the same purpose as the proposed capacity tool, however. Most selfassessment tools are one-dimensional, looking at one specific aspect of school improvement, such as leadership or decision-making, and focus on student achievement as the sole indicator of effectiveness.

Other tools that are multi-dimensional - for example, the Conditions for School Effectiveness Self Assessment in Massachusetts, which allows educators to see if their school meets 11 identified conditions for effectiveness (MA Dept. of Education, 2010) - do not sufficiently address the connections between the many moving parts in a school that can affect school improvement efforts, as well as predict future improvement outcomes. 
Investing in a high-quality capacity measurement tool that uses the framework put forth here and takes into account the interconnected nature of schooling would therefore likely yield myriad returns. Schools could use this tool to become aware of their areas of strength and weakness; researchers could identify trends in school, district, and regional deficiencies; and policymakers could better understand the needs of schools in their district or state. Most importantly, however, schoollevel personnel would - for perhaps the first time in many years - feel empowered to change their school for the better based on knowledge of their school's specific areas of strengths and weaknesses.

\section{Sources}

Bryk, A. S., \& Schneider, B. L. (2002). Trust in schools: A core resource for improvement. New York: Russell Sage Foundation.

Childress, S., Elmore, R., Grossman, A.S., King, C. (January 31, 2007). Note on the PELP Coherence Framework (PEL-010).

Public Education Leadership Project at Harvard University, Cambridge, MA.

Corcoran, T., \& Goertz, M. (1995). Instructional capacity and high performance schools. Educational Researcher, 24(9), 27-31.

Elmore, R.F. (2000). Building a new structure for school leadership. Washington, DC: Albert Shanker Institute.

Fullan, M. (2000). The return of large scale reform. Journal of Educational Change, 1, 5-28.

Gamoran,A., Gunter, R., \& Williams, T. (2005). Professional community by design: building social capital through teacher professional development. In L.V. Hedges and B. Schneider (Eds.), The Social Organization of Schooling. New York: Russell Sage Foundation.

Hargreaves, A., \& Fullan, M. (2012). Professional capital:Transforming teaching in every school. New York, Toronto:Teachers College Press.

Hatch, T. (2009). Managing to change: How schools can survive (and sometimes thrive) in turbulent times. New York, London: Teachers College Press.

Hill, H.C. (2007). Mathematical knowledge of middle school teachers: Implications for the No Child Left Behind policy initiative. Educational Evaluation and Policy Analysis, 29(2), 95-114.

Maryland Department of Education (2010). Indicators for Effective Principal Leadership in Improving Student Achievement. Retrieved February 6, 2012, from http://mdk12.org/ process/leading/p_indicators.html.

Massachusetts Department of Education (2010). Conditions for School Effectiveness Self Assessment. Retrieved February 6, 2012, from http://www.doe.mass.edu/ sda/ucd/CSESelf-Assesment.pdf.

Newmann, F. M., King, M. B., \& Youngs, P. (2000). Professional development that addresses school capacity: Lessons from urban elementary schools. American Journal of Education, 108(4), 259-299.

Newmann, F. M., Smith, B., Allensworth, E., \& Bryk, A. S. (2001). School instructional program coherence: Benefits and challenges. Chicago: Consortium on Chicago School Research.
O’Day, J., Goertz, M., \& Floden, R. (1995). Building capacity for education reform. (CPRE Policy Briefs \#RB-18). Philadelphia: Consortium for Policy Research in Education.

RISC (2012). Organizational Self-Assessment Tool. The Re-Inventing Schools Coalition (RISC). Retrieved February 6, 2012, from http://www.reinventingschools.org/wpcontent/uploads/2010/03/RISC-OSAT.pdf.

Rockoff, J.E., Jacob, B.A., Kane, T.J., \& Staiger, D.O. (2008). Can you recognize an effective teacher when you recruit one? NBER Working Paper 14485. Retrieved April 26, 2012 from Working Paper 14485 http://www.nber.org/papers/w14485.

Spillane, J. P., \& Thompson, C. L. (1997). Reconstructing conceptions of local capacity: The local education agency's capacity for ambitious instructional reform. Educational Evaluation and Policy Analysis, 19(2), 185-203.

\section{About the Authors:}

Jessica K. Beaver is a doctoral candidate in the Education Policy program at the University of Pennsylvania, and she is an Institute of Education Sciences Pre-Doctoral Fellow. Her research interests include decision-making in educational organizations, as well as the impact of the No Child Left Behind Act on student academic achievement. Previously, Ms. Beaver worked for a Member of Congress on education policy and education appropriations issues, and before that for a government relations firm specializing in education advocacy. She holds a B.A. from Cornell University.

Elliot Weinbaum is a Senior Researcher at the Consortium for Policy Research in Education and is a Research Assistant Professor at the University of Pennsylvania. His work focuses on the development of education policy and its impact on teacher and administrator practice and school improvement. Dr. Weinbaum is co-editor of The Implementation Gap: Understanding Reform in High Schools. His research investigates state-led efforts to improve classroom instruction and central office efforts to scale-up reform practices. Elliot holds a B.A. from Yale University and a Ph.D. from the University of Pennsylvania. 


\section{Policy Brief}

CONSORTIUM FOR POLICY RESEARCH IN EDUCATION

Non Profit

U.S. Postage

PAID

Permit No. 2563

Philadelphia, PA

\section{About the Consortium for Policy Research in Education (CPRE)}

Established in 1985, CPRE unites researchers from seven of the nation's leading research institutions in efforts to improve elementary and secondary education through practical research on policy, finance, school reform, and school governance. CPRE studies alternative approaches to education reform to determine how state and local policies can promote student learning. The Consortium's member institutions are the University of Pennsylvania, Teachers College-Columbia University, Harvard University, Stanford University, the University of Michigan, University of Wisconsin-Madison, and Northwestern University.

The University of Pennsylvania values diversity and seeks talented students, faculty, and staff from diverse backgrounds. The University of Pennsylvania does not discriminate on the basis of race, sex, sexual orientation, religion, color, national, or ethnic origin, age, disability, or status as a Vietnam Era Veteran or disabled veteran in the administration of educational policies, programs or activities; admissions policies, scholarships or loan awards; athletic, or University administered programs or employment.

Questions or complaints regarding this policy should be directed to Executive Director, Office of Affirmative Action, 1133 Blockley Hall, Philadelphia, PA 19104-6021 or (215) 898-6993 (Voice) or (215) 898-7803 (TDD).

\section{CPRE.ORG}

